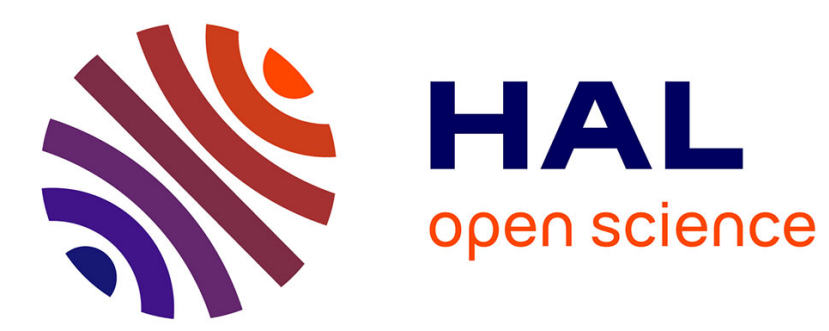

\title{
Effect of a long-term prior aging on the tensile behaviour of a high-performance single crystal superalloy
}

\author{
M. Pessah-Simonetti, P. Caron, T. Khan
}

\section{To cite this version:}

M. Pessah-Simonetti, P. Caron, T. Khan. Effect of a long-term prior aging on the tensile behaviour of a high-performance single crystal superalloy. Journal de Physique IV Proceedings, 1993, 03 (C7), pp.C7-347-C7-350. 10.1051/jp4:1993753 . jpa-00252171

\section{HAL Id: jpa-00252171 https://hal.science/jpa-00252171}

Submitted on 1 Jan 1993

HAL is a multi-disciplinary open access archive for the deposit and dissemination of scientific research documents, whether they are published or not. The documents may come from teaching and research institutions in France or abroad, or from public or private research centers.
L'archive ouverte pluridisciplinaire HAL, est destinée au dépôt et à la diffusion de documents scientifiques de niveau recherche, publiés ou non, émanant des établissements d'enseignement et de recherche français ou étrangers, des laboratoires publics ou privés. 


\title{
Effect of a long-term prior aging on the tensile behaviour of a high- performance single crystal superalloy
}

\author{
M. PESSAH-SIMONETTI, P. CARON and T. KHAN
}

ONERA, BP. 72, 92322 Châtillon cedex, France

\begin{abstract}
The influence of long-term aging heat treatments on the tensile behaviour of $<001>$ single crystals of the $\mathrm{MC} 2$ nickel-based superalloy was investigated at room temperature, 650 and $950^{\circ} \mathrm{C}$. The precipitation of brittle particles of a W-rich $\mu$ phase did not induce any deleterious effect on the tensile strength and ductility. The decrease in yield strength and the increase in ductility were attributed to the coarsening of the $\gamma^{\prime}$ strengthening particles which promotes by-passing of the precipitates by matrix dislocations and the homogeneization of deformation.
\end{abstract}

\section{Introduction}

Single crystalline $\gamma / \gamma^{\prime}$ nickel-based superalloys are used as turbine blade and vane materials in aeronautical engines. The $\mathrm{MC} 2$ alloy shows a very high creep strength, especially at temperatures above $1000^{\circ} \mathrm{C}$, resulting partly from the large content of $\mathrm{Mo}$ and $\mathrm{W}$, which, in return, renders the alloy prone to the precipitation of $\mathrm{W}$-rich $\mu$ phase particles during prolonged exposures at temperatures above $850^{\circ} \mathrm{C}$ [1]. Concurrently, the creep conditions lead to the oriented coarsening of the strengthening $\gamma$ ' precipitates as rafts normal to the $<001>$ stress axis. This study was aimed at evaluating the effects of such microstructural instabilities on the tensile behaviour of $<001>M C 2$ single crystal specimens.

\section{Experimental Procedure}

Dendritic single crystal rods were directionally cast by the withdrawal process on $<001>$ seeds. The chemical composition (wt.\%) of the heat was : Ni-7.89Cr-5.08Co-2.11Mo-7.99W-5.05Al-1.49Ti-5.96Ta. The single crystals were applied the following standard heat-treatment cycle : $1300^{\circ} \mathrm{C} / 3$ hours/A.C. + $1100^{\circ} \mathrm{C} / 4$ hours/A.C. $+850^{\circ} \mathrm{C} / 24$ hours/A.C. resulting in a homogeneous distribution of cuboidal $\gamma^{\prime}$ particles aligned along the $<001>$ directions and with a mean edge size of $0.35 \mu \mathrm{m}$ (Figure 1a). Cylindrical tensile specimens with a $4 \mathrm{~mm}$ diameter and a $30 \mathrm{~mm}$ gauge length were machined from these rods. Some plate specimens were prepared with mecanichally polished faces parallel to $\{001\}$ planes in order to observe the slip bands.

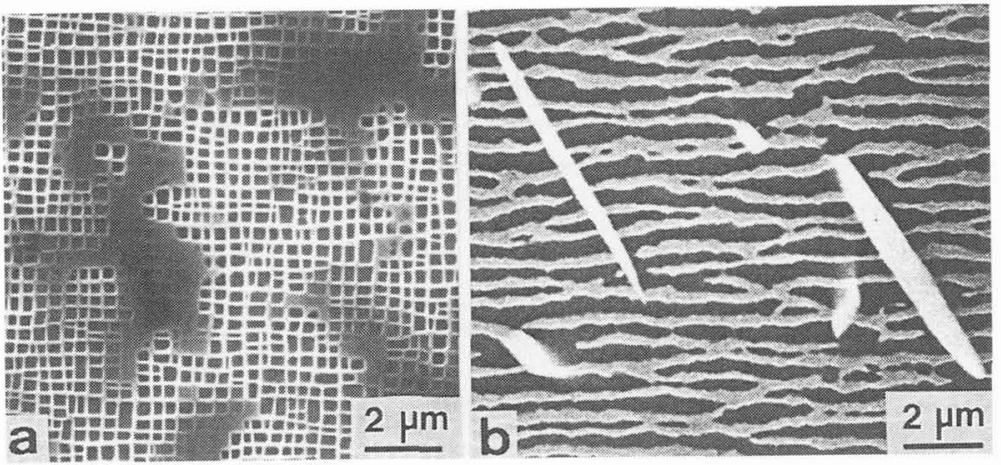

Figure 1 : Microstructures of MC2 single crystals :

a) standard heat treatments : $1300^{\circ} \mathrm{C} / 3$ hours/A.C. + $1100^{\circ} \mathrm{C} / 4$ hours/A.C. + $850^{\circ} \mathrm{C} / 24$ hours/A.C. ;

b) standard heat treatments + 200 hours at $1050^{\circ} \mathrm{C}$ under $80 \mathrm{MPa}$ (longitudinal section). 

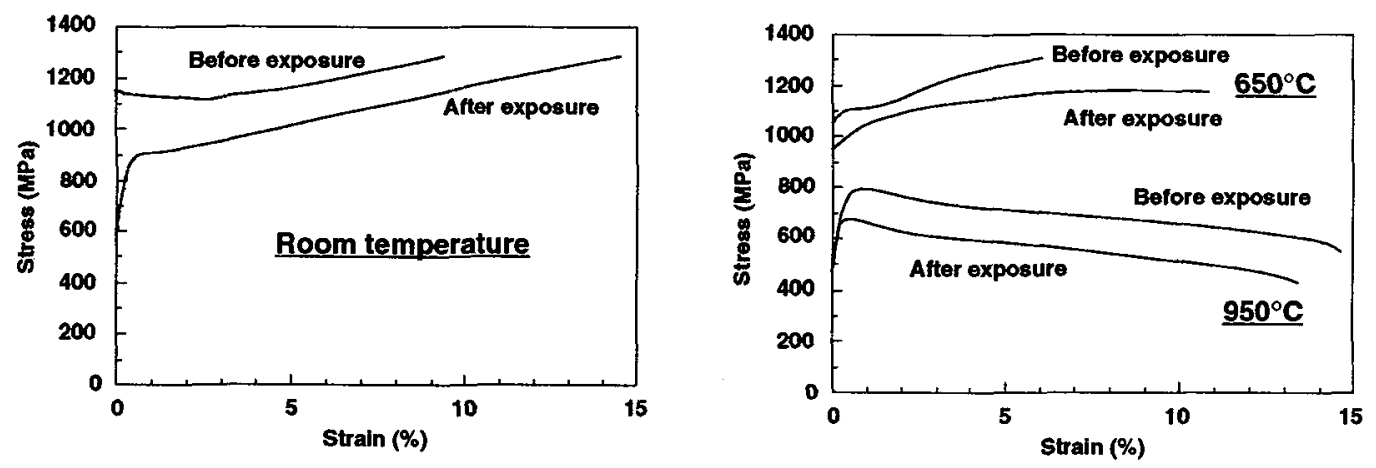

Figure 2 : Effect of temperature and of an exposure for 200 hours at $1050^{\circ} \mathrm{C}$ and $80 \mathrm{MPa}$ on the engineering stress-strain tensile curves of $\angle 001>\mathrm{MC} 2$ single crystals .

Half of the tensile specimens were subjected to a prior tensile creep test for 200 hours at $1050^{\circ} \mathrm{C}$ and 80 $\mathrm{MPa}$. The resulting microstructure is illustrated in Figure $1 \mathrm{~b}$. The $\gamma^{\prime}$ particles have coarsened as rafts normal to the $<001>$ stress axis. Their thickness is close to the size of the initial cuboidal precipitates, and their length may attain several tens of micrometers. Some particules of a W-rich phase precipitated within the core of the dendrites. These precipitates appear as needles or as spheroidal particles. Observations on different sections of the specimens showed that the needle-like particules are platelets with a thickness of about $0.5 \mu \mathrm{m}$ and a length which may attain $25 \mu \mathrm{m}$. The globular particules have a diameter close to 1 $\mu \mathrm{m}$. The $W$-rich phase has been identified as a rhombohedral T.C.P. (topologically close packed) $\mu$ phase with parameters close to $\mathrm{a}=8,94 \AA$ and $\alpha=30^{\circ} 50^{\prime}$. The localized precipitation of the $\mu$ phase within the dendrite cores is due to a residual segregation of $W[2]$. The volume fraction of $\mu$ phase in the aged specimens was evaluated to be less than $0.5 \%$.

Tensile tests were conducted on aged and unaged specimens in air at room temperature and in argon at 650 and $950^{\circ} \mathrm{C}$. The tests were performed with a constant crosshead speed corresponding to an initial strain rate of $1.1 .10^{-4} \mathrm{~s}^{-1}$. Some tests were interrupted before failure in order to produce samples for T.E.M. analysis of the deformation mechanisms.

\section{Experimental Results}

Typical engineering stress/strain curves are shown in Figure 2 . The tensile data are reported in Table 1. The main effects of the aging treatment on the tensile behaviour at 25 and $650^{\circ} \mathrm{C}$ of the $\mathrm{MC} 2$ single crystals are $:$ i) the decrease of the yield strength, ii) the reduction of the length of the plateau region following the yield stress, iii) the increase of the ductility. At $950^{\circ} \mathrm{C}$, the yield strength and the ductility are not affected by prior aging but the ultimate tensile strength is significantly reduced.

The observation of fracture surfaces by scanning electron microscopy showed that the aging treatment did not affect the fracture mechanism eventhough, locally, $\mu$ particles were found broken, attesting their brittle behaviour. Observation of longitudinal sections of aged specimens tested at 25 and $650^{\circ} \mathrm{C}$ revealed that some of the $\mu$ phase precipitates are fractured (Figure 3). The amount of broken $\mu$ phase particles is increased near the rupture surface. The broken particles were segmented in many parts, but these cracks never propagated into the matrix. Furthermore, decohesion at the interface between $\mu$ phase particles and the superalloy matrix occured very rarely and never initiated crack propagation in the single crystal specimen.

Table 1 : Effect of a long-term aging treatment for 200 hours at $1050^{\circ} \mathrm{C}$ and $80 \mathrm{MPa}$ on the tensile properties of $<001>$ single crystals of the MC2 alloy.

\begin{tabular}{|c|c|c|c|c|c|c|}
\hline \multirow[b]{2}{*}{$\begin{array}{c}\text { Temperature } \\
\left({ }^{\circ} \mathrm{C}\right)\end{array}$} & \multicolumn{3}{|c|}{ Unaged } & \multicolumn{3}{|c|}{ Aged } \\
\hline & $\begin{array}{c}0.2 \% \mathrm{Y} . S . \\
(\mathrm{MPa})\end{array}$ & $\begin{array}{l}\text { U.T.S. } \\
(\mathrm{MPa})\end{array}$ & $\begin{array}{c}\text { Elongation } \\
(\%)\end{array}$ & $\begin{array}{c}0.2 \% \mathrm{Y} . \mathrm{S} \\
(\mathrm{MPa})\end{array}$ & $\begin{array}{l}\text { U.T.S. } \\
\text { (MPa) }\end{array}$ & $\begin{array}{c}\text { Elongation } \\
(\%)\end{array}$ \\
\hline 25 & 1146 & 1292 & 9.0 & 887 & 1213 & 13.1 \\
\hline 25 & 1133 & 1214 & 9.1 & 854 & 1286 & 14.5 \\
\hline 650 & 1089 & 1299 & 6.1 & 967 & 1171 & 10.9 \\
\hline 650 & 1070 & 1261 & 6.1 & 998 & 1228 & 9.5 \\
\hline 950 & 616 & 793 & 15.2 & 656 & 662 & 13.1 \\
\hline 950 & 659 & 799 & 16.7 & 621 & 665 & 10.1 \\
\hline
\end{tabular}




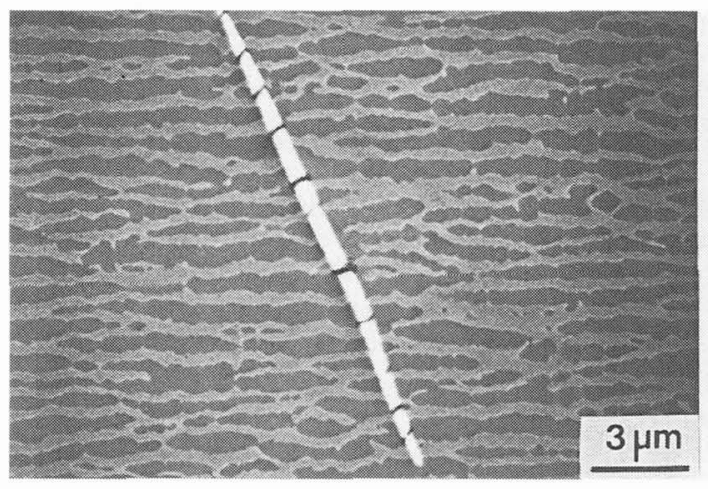

Figure 3 : Longitudinal section of an aged MC2 tensile specimen tested at room temperature.

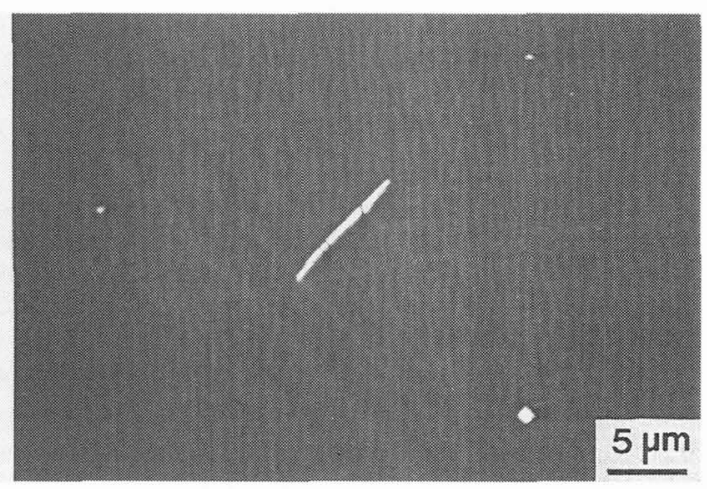

Figure 4 : Surface of an aged MC2 plate specimen after $0.6 \%$ of plastic strain at R.T.

In specimens tested at $950^{\circ} \mathrm{C}, \mu$ phase particles were not found to be broken.

After deformation in the plateau region, the surface of the plate specimens tested at room temperature exhibited deformation bands parallel to $\{111\}$ planes, both in the aged and unaged materials. In the aged material, $\mu$ phase platelets are found broken in several parts when they are intersected by a deformation band (Figure 4).

T.E.M. observations of tensile specimens tested at $25^{\circ} \mathrm{C}$ confirmed that, both in the unaged and aged structures, the deformation is mainly concentrated in planar slip bands where a high density of superlattice stacking fault loops was observed within the $\gamma^{+}$precipitates (figure 5). The faults are bounded by a $a / 3<112>$ partial and lie on the $\{111\}$ plane parallel to the deformation band. Outside these bands, the deformation occured primarily by $\mathrm{a} / 2<110>$ dislocation bypass of the $\gamma^{\prime}$ precipitates. Moreover, some tightly constricted $a / 2<110>$ dislocation pairs were identified within the precipitates. The faulted loops, unusual in superalloys after low temperature deformation, have been reported only in in the case of the PWA 1480 single crystal alloy [3]. It was proposed that the $\gamma^{\prime}$ are sheared by $a<110>$ dislocations that leave faulted loops as deformation debris. Indeed, if the superlattice stacking fault energy is low compared to the antiphase boundary energy, a a $[\overline{1} 01]$ dislocation may dissociate inside a $\gamma^{\prime}$ precipitate via the follo-

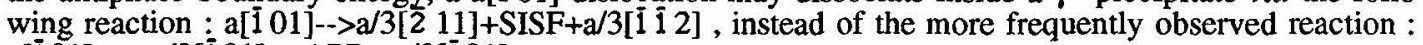
$\mathrm{a}[\overline{1} 01]-\rightarrow \mathrm{a} / 2[\overline{1} 01]+\mathrm{APB}+\mathrm{a} / 2[\overline{1} 01]$.

\section{Discussion}

According to the literature, two mechanisms are proposed to explain the deleterious effect of T.C.P. brittle phases, such as $\sigma, \mu$ or Laves phases, in polycrystalline superalloys [4]. The first one is a softening of the $\gamma$ matrix consecutive to its impoverishment in refractory elements which participate in the $\mu$ phase formation. Considering the low amount of $\mu$ phase precipitating in MC2 alloy $(<0.5$ vol.\%), this effect must be negligible. The second effect which could be expected is the initiation of cracks at the interface between matrix and T.C.P. phase particles. This event has never been observed in the case of MC2 superalloy. The good cohesion of these interfaces is in agreement with the results of a recent study aiming at
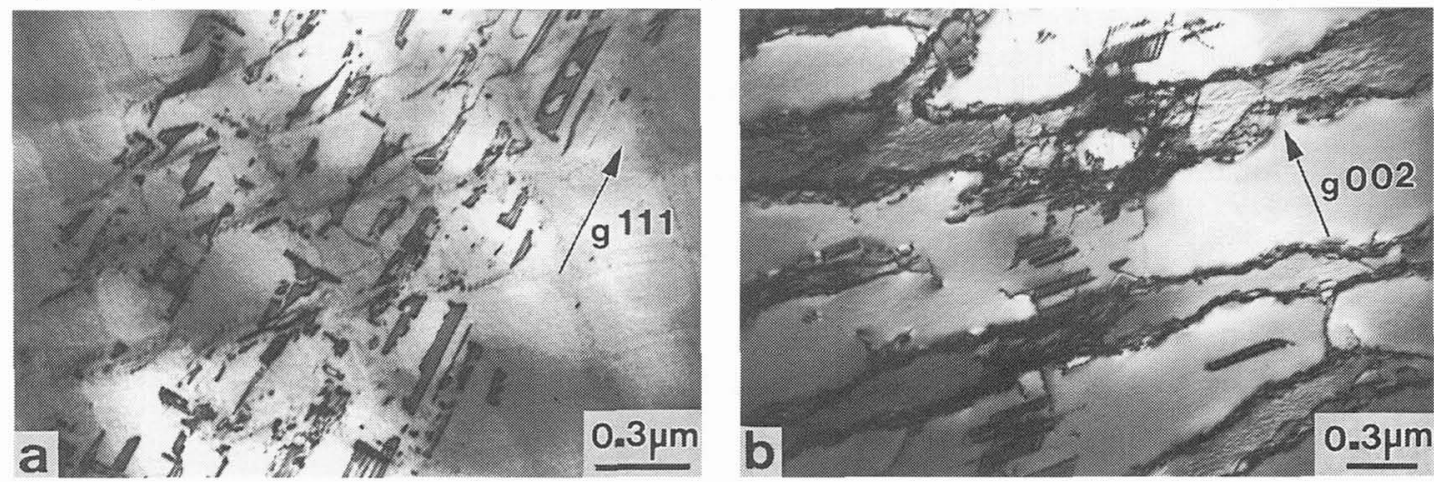

Figure 5 : Dislocation structures in tensile specimens strained to $2 \%$ at room temperature : (a) unaged material, (b) aged material. 
identifying the orientation relationships (O.R.) existing between $\mu$ phase precipitates and the matrix. Indeed, we have shown that the two O.R. which are the most frequently encountered generate good coincidence between both $\gamma / \gamma^{\prime}$ and $\mu$ lattices, which could explain the further strong cohesion of the interfaces. This two O.R. are respectively $(111)_{\mu} / /(111)_{\gamma / \gamma^{\prime}}$ and $[01 \overline{1}]_{\mu} / /[11 \overline{2}]_{\gamma / \gamma^{\prime}}$, and $(111)_{\mu} / /(210)_{\gamma / \gamma^{\prime}}$ and $[01 \overline{1}]_{\mu} / /[001]_{\gamma / \gamma^{*}}$.

The observation of broken $\mu$ phase particles facing deformation bands at $25^{\circ} \mathrm{C}$ tends to support the hypothesis that stress concentration due to dislocation pile-up's at the interface is at the origin of the fracture of these particles similar to the case of COTAC/NITAC type composites [5]. At $950^{\circ} \mathrm{C}$, the pile-up mechanism probably does not occur anymore; $\gamma^{\prime}$ precipitates as well as $\mu$ phase precipitates must be bypassed by matrix dislocations by a combination of slip and climb mechanisms thus explaining that $\mu$ phase particles are not found broken after testing at this temperature.

Since the presence of $\mu$ phase particles was not be found responsible for the changes in tensile properties resulting from the aging treatment, the effects observed were attributed to the $\gamma^{\prime}$ precipitate coarsening. Previous studies on the tensile behaviour of single crystal superalloys have shown that the deformation initiated by the bowing of $a / 2<011>$ dislocations through the $\gamma$ matrix channels [6]. The motion of these dislocations is thus primarily controlled by the Orowan stress, $\tau_{\text {or }}=\mu \mathrm{b} / 1$, where $\mu$ is the matrix shear modulus, $b$ the Burgers vector and 1 the width of the $\gamma$ channel along the glide direction. The Orowan stress is obviously lower in the aged material where the mean value of the spacing between $\gamma^{\prime}$ rafts was evaluated close to $270 \mathrm{~nm}$, than in the unaged alloy where the $\gamma$ corridor mean size is close to $30 \mathrm{~nm}$ (see Figure 1). It can therefore explain, at less qualitatively, the decrease in yield strength observed at room temperature and $650^{\circ} \mathrm{C}$ after aging at $1050^{\circ} \mathrm{C}$. This hypothesis is supported by the fact that the aged material yielded more smoothly at room temperature $(0.5 \%$ of plastic strain before the plateau region) implying larger amount of deformation in the matrix before the precipitates were sheared. Furthermore, the reduction of the length of the heterogeneous deformation stage and the increase of ductility in the aged single crystals can be related to the homogeneization of the deformation resulting from the multiplication of dislocation sources in the $\gamma$ matrix of the rafted structure. The decrease of the ultimate tensile strength observed in the overaged single crystals at $950^{\circ} \mathrm{C}$ will be interpreted on the basis of dislocation structure analysis which are presently at hand.

\section{Conclusions}

The main conclusions of this study are :

$1 /$ The presence of a low volume fraction $(<0,5 \%)$ of $\mu$ phase particles induced by a long-term aging heat-treatment for 200 hours at $1050^{\circ} \mathrm{C}$ under $80 \mathrm{MPa}$ did not lead to any deleterious effect on the tensile behaviour at 25,650 and $950^{\circ} \mathrm{C}$ of $<001>$ single crystals of the MC2 superalloy.

$2 /$ The oriented coarsening of the $\gamma^{\prime}$ precipitates resulting from this overaging heat treatment results in a reduction of the yield strength and a homogeneisation of the deformation at 25 and $650^{\circ} \mathrm{C}$. At $950^{\circ} \mathrm{C}$, the yield strength remains unchanged, but the ultimate tensile strength decreases.

\section{Acknowledgements}

The authors acknowledge the D.R.E.T. for financial support and Dr. L.P. Kubin for fruitful discussions.

\section{References}

[1] Caron P. and Khan T., Advanced Materials and Processes, Vol.1 : Advanced Processing and High Temperature Materials, ed : H.E. Exner and V. Schumacher, DGM Informationgesellschaft mbH, Oberursel, RFA (1990) 333-338.

[2] Pessah M., Caron P. and Khan T., SUPERALLOYS 92, ed. S.D. Antolovich et al., TMS, Warrendale, PA, U.S.A. (1992) 567-576.

[3] Milligan W.W. and Antolovich S.D., Met. Trans. A, 22A (1991) 2309-2318.

[4] Sims C.T. , SUPERALLOYS II, chap. 8, ed. C.T. Sims, N.S. Stoloff and W.C. Hagel, John Wiley \& Sons, New York, NY, U.S.A. (1987), 217-240.

[5] Stohr J.F. and Valle R., Phil. Mag., 32 (1975) 43-59

[6] Lisiecki B., Doctoral thesis, Université Pierre et Marie Curie, Paris, France, 1992. 